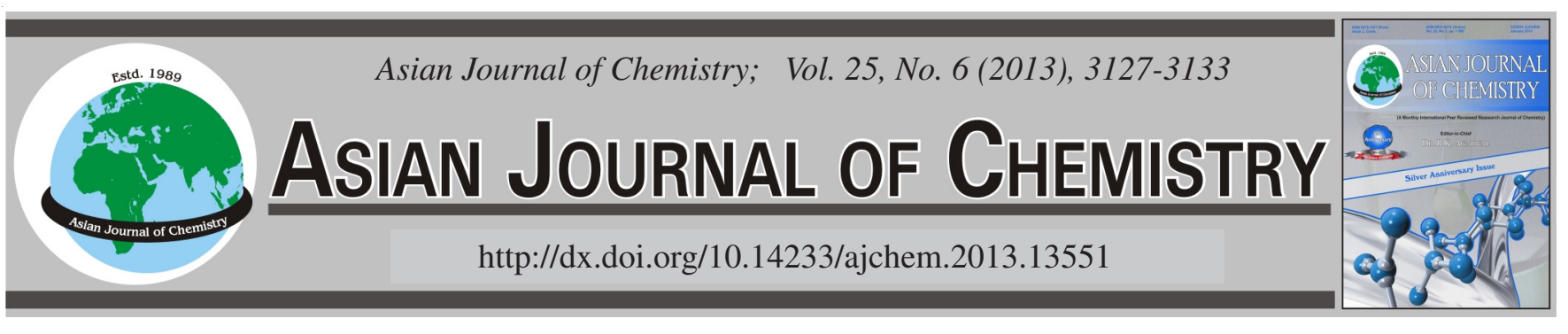

\title{
Composition of Flavan-3-ol Monomers in Mature Cabernet Sauvignon Fruit at Different Grapevine Age in Yantai, China
}

\author{
Xinje Zhao ${ }^{1}$, Bo Deng ${ }^{1}$, JingXia Mu ${ }^{1}$, Chunguang $\mathrm{Li}^{2}$, Feng Wu$^{2}, \mathrm{Ning}_{\mathrm{Han}}{ }^{1, *}$ and Yueling ZhaO ${ }^{1}$
}

${ }^{1}$ Shandong Provincial Key Laboratory of Microbial Engineering, Shandong Polytechnic University, Ji'nan 250353, Shandong, P.R. China ${ }^{2}$ China Oil and Foodstuffs Corporation, Great Wall Wine (Yantai) Co. Ltd., Yantai 265600, Shandong, P.R. China

*Corresponding author: Fax: +86 531 89631182; Tel: +86 531 89631182; E-mail: hn8265@163.com

(Received: 3 February 2012;

Accepted: 12 December 2012)

AJC-12533 We have identified the phenols, tannins and the primary flavan-3-ol monomers including (+)-catechin, $(-)$-epicatechin, $(+)$-gallocatechin
grade, $(-)$-epigallocatechin, $(-)$-catechin gallate, (-)-epicatechin, gallocatechin gallate and (-)-epigallocatechin gallate in different tissues
(flesh, peduncle, skin and seed) of 5 year and 10 year grapevines grape (Cabernet sauvignon) and quantified their content by high
performance liquid chromatography. The results show that there were significant differences in the concentration of phenols, tannins and
the primary flavan-3-ol monomers among different tissues and grapevine age. Especially, the concentrations of flavan-3-ol monomers
were higher in all four grape tissues of 10 year grapevines grape than those of 5 year one. In terms of $(-)$-catechin gallate, it was detected
only in 10 year grapevines grape berry and the flesh of 5 -year grapevines grape. The concentrations of $(+)$ - catechin and (-)-epicatechin
in the seeds of 10 -year grapevines grape were about twice as much as those in 5 year ones.

Key Words: Flavan-3-ol, Phenols, Monomers, Grapevine age, Cabernet sauvignon.

ᄂ - - - - - - - - - - - - - - - - - - - - - - - - - - - -

\section{INTRODUCTION}

Such phenolics as (gallo) catechins and proanthocyanidins play a relevant role in the quality of products, especially for red wine, because of their wine sensory characteristics. These compounds are present in grape seeds and skins, which undergo structural transformations through oxidation and condensation reactions during wine making and wine ageing processes ${ }^{1,2}$. Flavan-3-ol is one of the major parts of phenolic compound that determines wine quality and style and it has been found to closely relate to antioxidant ${ }^{3}$, anticancer ${ }^{4}$, antithrombosis ${ }^{5}$ and cardiovascular protection ${ }^{6}$. Several authors have studied the flavan-3-ol content in different types of grapes, as well as the content variations among berries developed in different climatic conditions ${ }^{7-13}$. The phenolic compounds in grape berries depend on the climatic and geographical conditions, cultural practices, stage of ripeness and vegetative vigor of the plant, in which the last two have made important contributions to the genetic aspects such as vine cultivar, clone and rootstock $^{14,15}$. The existing researches have shown that the phenolic concentration reaches its highest value at veraison and decreases slightly until near maturity stage where it remains relatively constant.

Flavan-3-ols are present in both the grape seeds and skins $^{8,16-18}$, however, grape seeds contain much higher concen- tration of flavan-3-ols than skins and have varying compositions of catechins and procyanidins, whereas skins possess both catechins and gallocatechins and their corresponding derived proanthocyaidins (i.e., procyanidins and prodelphinidins). Besides catechin, epicatechin has been identified in both seeds and skins as the vital individual flavanol ${ }^{9,10}$. Cabernet sauvignon variety of grape is one of the most widely recognized red grapes in the world and has the highest proportion of monomeric flavan-3-ol (47\%), followed by Tempranillo (38\%) and Graciano $(31 \%)$ in Monagas ${ }^{19}$ studies. However, it is not clear about the content of phenolic (flavan-3-ols) in different grape tissues at maturity, as well as the composition diversity of monomeric flavan-3-ol at different grapevine age (5-year and 10-year).

In the present study, we have evaluated the flavan-3-ols composition in different Cabernet sauvignon grape tissues and investigated the influence of grapevine age on flavan-3-ols content from different grape tissues in Yantai. Given the climatic conditions of Yantai in 2010 (often raining for a half month before grape age are harvested), we have adopted a low activation of flavanol pathway.

\section{EXPERIMENTAL}

Flavan-3-ols standards, including (+)-catechin (CAT), (-)-epicatechin (EC), (+)-gallocatechin grade (GC), (-)- 
epigallocatechin (EGC), (-)-catechin gallate (EGCC), (-)epicatechin (ECG), gallocatechin gallate (GCG) and (-)epigallocatechin gallate (EGCG) were purchased from Sigma Chemical Co. (St. Louis, USA). Deionized water was purified with a Veolia water system (Paris, France). Acetonitrile and methanol were of HPLC grade (TEDIA, FAIRFLELD, USA) and Folin Ciocalteu's phenol and vanillin were purchased from SINOPHARM (SHANGHAI, CHINA). Ethyl acetate, ethanol, acetone, petroleum ether, chloroform, sodium sulfite, sodium carbonate, muriatic acid (37\%), ammonium sulfate, metaphosphoric acid were all purchased from local chemical reagent company and analytical grade.

Grape samples: Cabernet sauvignon (vintaged in Oct, 2010) were harvested at our technological maturity from the same vineyard (Great Wall vineyards of COFCO) located in Yantai (Shandong, China). Vines were planted $0.8 \mathrm{~m}$ within the rows and $1.5 \mathrm{~m}$ between rows and trained to bilateral cordons with shoots trained vertically. Soils in the vineyard were uniform. Moreover, agronomic, photochemical and technical variables were controlled. We randomly selected 1012 clusters of maturity grape sample from the collected samples of each mold (5-year and 10-year grapevines grape) and kept the peduncles attached to minimize oxidation. Grape peduncles, skins, fleshes and seeds were separated manually and they were frozen at $-18^{\circ} \mathrm{C}$ under nitrogen for subsequent analysis.

Analysis of the total phenol: The frozen skins, peduncles, flesh and seeds were finally ground in a ball grinder (berries were crushed by juice extraction device). $5 \mathrm{~g}$ obtained powder was mixed with $0.1 \mathrm{~mL}$ sodium sulfite $(0.1 \%)$ and $100 \mathrm{~mL}$ alcohol/water (70/30, v/v) and ultrasonic extracted for $0.5 \mathrm{~min}$. The centrifugal supernatants were combined and evaporated under reduced pressure at $30^{\circ} \mathrm{C}$ to remove organic solvents. The residue was dissolved in methanol with the total volume of $100 \mathrm{~mL}$. The following solutions were transferred to a 100 $\mathrm{mL}$ flask: $1 \mathrm{~mL}$ solubilized crude extract, $5 \mathrm{~mL}$ Folin Ciocalteu solution, $15 \mathrm{~mL} \mathrm{Na}_{2} \mathrm{CO}_{3}$ solution and deionized water up to the mark and kept for $2 \mathrm{~h}$ at $20^{\circ} \mathrm{C}$. The absorbance was measured at $760 \mathrm{~nm}$ wavelength with a UV-VIS spectrophotometer (722 models, SHANGHAI SPECTRUM). Standard curve configuration: Standard liquids for calibrating viscometers, gallic acid $\left(1 \mathrm{mg} \mathrm{mL} \mathrm{m}^{-1}\right), \mathrm{Y}=0.9638 \mathrm{X}-0.0041\left(\mathrm{R}^{2}=0.9997\right)$. All experiments were performed in triplicate.

Analysis of the total tannin: Using Vanillin-hydrochloric acid method ${ }^{16}$, we detected the content of flavanol and polyanthocyanidin in samples by adding $0.25 \mathrm{~mL}$ drips $\mathrm{Na}_{2} \mathrm{SO}_{3}$ and $100 \mathrm{~mL}$ acetone/water $(70: 30, \mathrm{v} / \mathrm{v})$ in $5 \mathrm{~g}$ of solubilized crude extract, followed by three times extraction in ultrasonic, $0.5 \mathrm{~h}$ each time. The centrifugal supernatants were combined and concentrated in a rotary evaporator at $30^{\circ} \mathrm{C}$. The residue was dissolved in methyl alcohol. Then we prepared $100 \mathrm{~mL}$ solution of $0.5 \mathrm{~mL}$ solubilized crude extract, $3 \mathrm{~mL}$ Vanillin methanol soluble $(4: 96, \mathrm{v} / \mathrm{v}), 1.5 \mathrm{~mL} \mathrm{HCl}(12 \mathrm{M})$ and deionized water in a brown flasks, which continued to react for $40 \mathrm{~min}$ at $20^{\circ} \mathrm{C}$, followed by the examination with a UV absorptiometry at $510 \mathrm{~nm}$. Standard curve configuration: Standard liquids for calibrating viscometers, $(+)$-catechin $\left(0.5 \mathrm{mg} \mathrm{mL}^{-1}\right)$, $\mathrm{Y}=0.1325 \mathrm{X}-0.0021\left(\mathrm{R}^{2}=0.998\right)$. All experiments were performed in triplicate.
HPLC analysis of monomeric flavan-3-ol: Five $\mathrm{g}$ berries (including seed, flesh, skin and peduncle), fleshes, peduncles, seeds or skins were mixed with $200 \mathrm{~mL}$ cold $65 \%$ ethanol consisting of thimbleful $\mathrm{Na}_{2} \mathrm{~S}_{2} \mathrm{O}_{5}(0.5 \%)$ and grounded for $0.5 \mathrm{~h}$ in a ball grinder at ice-bath condition. The mixture was then centrifuged for $5 \mathrm{~min}$ at $6^{\circ} \mathrm{C}(5000 \mathrm{rpm} / \mathrm{min}$, three times $)$. The centrifugal supernatants were combined and evaporated under reduced pressure at $40{ }^{\circ} \mathrm{C}$ to remove organic solvents and the residue was extracted three times by the same volume petroleum ether to get rid of pigment. The sublayer was dissolved in ammonium sulfate (20:80, v/v) and metaphosphoric acid $(2: 98, \mathrm{v} / \mathrm{v})$ and extracted three times by the same volume of ethyl acetate. The centrifugal supernatants were combined and dried in a rotary evaporator at $45^{\circ} \mathrm{C}$, with the crystals (or residue) re-dissolved in $5 \mathrm{~mL}$ methanol, the extract filtered through a $0.45 \mu \mathrm{m}$ pore size membrane before analyzing by HPLC.

Five $\mathrm{g}$ fresh, skins, fleshes and seeds were manually separated quickly. The flesh was weighed accurately, introduced to a $250 \mathrm{~mL}$ conical flask that contained the same volume of acetone:water (66:34, v/v) and extracted for $24 \mathrm{~h}$ under dark, room temperature and nitrogen atmosphere. Then, the sample was filtered by vacuum filter and evaporated under reduced pressure at $40{ }^{\circ} \mathrm{C}$ to remove acetone, which was then introduced into a $50 \mathrm{~mL}$ flask that was filled with deionized water up to the mark and filtered by $0.45 \mu \mathrm{m}$ microfiltration membrane $(0.45 \mu \mathrm{m})$ prior to analysis by HPLC.

Analysis of monomeric flavan-3-ol was performed with Agilent 1200 high performance liquid chromatography (Agilent Technologies, Palo Alto, CA, USA) that are composed of an online vacuum degasser, a Thermo-Finnigan UV-VIS detector (UV-VIS 200), an autosampler, a diode array detector (DAD), ChemStation chromatographic data treatment system. The experimental details include: Agilent $\mathrm{C}_{18}$ column $(250 \mathrm{~mm}$ $\times 4.6 \mathrm{~mm}, 5 \mu \mathrm{m}$ ) was kept at $30^{\circ} \mathrm{C}$; methanol as solvent $\mathrm{A}$, water containing $0.2 \%(\mathrm{v} / \mathrm{v})$ formic acid aqueous solution as solvent $\mathrm{B}$; the gradient profile began at $1-25 \% \mathrm{~A}$ at $25 \mathrm{~min}$, $35 \% \mathrm{~A}$ at $40 \mathrm{~min}$ and returned to the initial conditions $(1 \% \mathrm{~A})$ at $45 \mathrm{~min}$ and lasted for $5 \mathrm{~min}$; the flow rate was $1.0 \mathrm{~mL} / \mathrm{min}$; the eluting peaks were monitored at $280 \mathrm{~nm}$. All experiments were performed in triplicate.

Identifying flavan-3-ol monomers by HPLC: We identified the flavan-3-ol monomers by HPLC, as well as the fractionation and quantification of these compounds. Chromatogram of eight types of flavan-3-ol monomers standard sample was shown in Fig. 1.

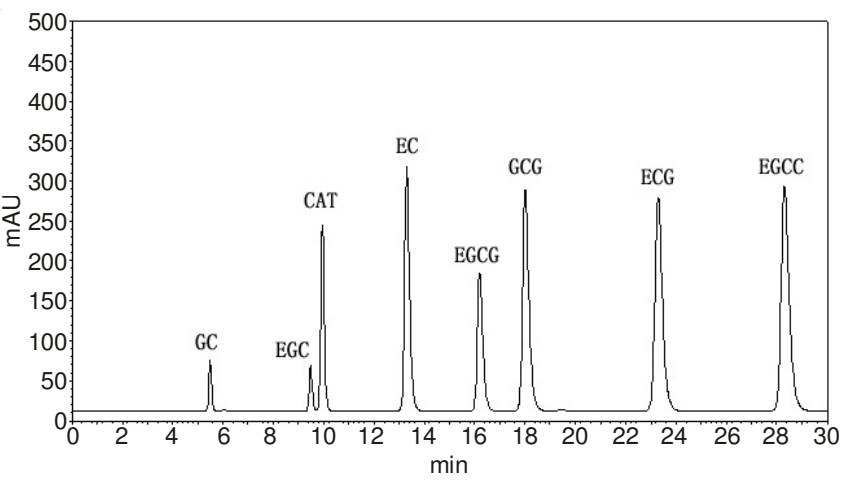

Fig. 1. HPLC chromatograms of eight kinds of flavan-3-ol monomers standard sample recorded at $280 \mathrm{~nm}$ 
Analysis of the total reducing sugar: Lane and Eynon analysis. The analysis of total acid: direct titration method (GB-15038).

Statistical analysis: Statistical analysis was performed with a statistical software package origin (version 6.0, Microsoft Company, Hampton, Massachusetts, US). ANOVA $(\mathrm{P}<0.05)$ indicated that the samples were significantly different. Adobe Photoshop CS3 extended was used in HPLC chromatogram.

\section{RESULTS AND DISCUSSION}

Basic physicochemical indexes of five-year and tenyear grape: Table-1 listed the parameter of reducing sugar, total acid and $\mathrm{pH}$ of grape berry. Reducing sugar is a critical factor in evaluating the quality of wine, i.e. the grape's reducing sugar could reach 210-230 $\mathrm{g} \mathrm{L}^{-1}$ at véraison in Australia's Coonawarra region, one of the superior wine making regions in the world. In this study, we found relatively low concentration of reducing sugar ( $c a .170 \mathrm{~g} \mathrm{~L}^{-1}$ indicating the grape was at maturity) with no significant differences between the 5-year and 10-year grape at maturity, which is likely to the weather condition in Yantai where it regularly rains for a half month before grape harvesting.

\begin{tabular}{lcc}
\multicolumn{2}{c}{ TABLE-1 } \\
PARAMETERS OF REDUCING SUGAR, TOTAL ACID AND \\
pH OF CABERNET SAUVIGNON GRAPE BERRY
\end{tabular}

Table- 2 showed that the highest content of total phenol in the grapes tissues (peduncles, fleshes, skins, seeds) was seeds in both five-year and ten-year grapevines grape with the concentrations of 43.97 and $50.07 \mathrm{mg} \mathrm{g}^{-1}$, respectively, followed by those in skins, peduncles and fleshes which accounts for $1.57 \%$ (0.69 $\mathrm{mg} \mathrm{g}^{-1}$, five-year) and $1.34 \%(0.67$ $\mathrm{mg} \mathrm{g}^{-1}$, ten-year) of total phenol in the seeds, respectively. This result was consistent with previous studies ${ }^{20,21}$, though some authors was ascribed to the flavanol composition of wine in spite of the lower content of phenolic compounds because skins were easier to extract than seeds $s^{21,22-24}$. In Table-2, the total phenolic content (TPCs) in the seeds and peduncles of tenyear grapevines grape (50.07 and $14.72 \mathrm{mg} \mathrm{g}^{-1}$, respectively) are higher than those in five-year ones (43.97 and $12.79 \mathrm{mg} \mathrm{g}^{-1}$, respectively). Further statistical analyses show that the TPCs are significantly different between seeds and peduncles and seeds have higher concentration of phenolic compounds.

As compared to other tissues, the high content of tannins was accumulated in the seeds of both five-year and ten-year grapevines grape compared to other tissues, but few tannins in flesh grape (Table-2). In addition, the content of tannins in peduncles, skins and seeds of ten-year grapevines grape (3.20, 4.47 and $29.69 \mathrm{mg} \mathrm{g}^{-1}$, respectively) were significantly less than those in five-year ones $\left(6.82,4.78\right.$ and $33.35 \mathrm{mg} \mathrm{g}^{-1}$ respectively).
TABLE-2

LEVELS TOTAL PHENOLIC COMPOUNDS AND TANNIN IN BERRY, FLESH, SEED, SKIN AND PEDUNCLE FROM DIFFERENT GRAPEVINE AGE CS GRAPE (FIVE-YEAR, TEN -YEAR)

\begin{tabular}{llcc}
\hline & Tissues & Five-year grape & Ten-year grape \\
\hline $\operatorname{TPC}^{*}\left(\mathrm{mg} \mathrm{g}^{-1}\right)$ & Berry & $3.54 \mathrm{a} \pm 0.00$ & $4.42 \mathrm{~b} \pm 0.19$ \\
& Flesh & $0.69 \mathrm{a} \pm 0.017$ & $0.67 \mathrm{a} \pm 0.010$ \\
& Peduncle & $12.79 \mathrm{a} \pm 0.22$ & $14.72 \mathrm{~b} \pm 0.23$ \\
& Skin & $5.98 \mathrm{a} \pm 0.22$ & $5.57 \mathrm{~b} \pm 0.12$ \\
& Seed & $43.97 \mathrm{a} \pm 1.11$ & $50.07 \mathrm{~b} \pm 1.93$ \\
\hline $\mathrm{TC}^{*}\left(\mathrm{mg} \mathrm{g}^{-1}\right)$ & Berry & $1.12 \mathrm{a} \pm 0.08$ & $1.48 \mathrm{~b} \pm 0.01$ \\
& Flesh & $0.20 \mathrm{a} \pm 0.01$ & $0.227 \mathrm{a} \pm 0.02$ \\
& Peduncle & $6.82 \mathrm{a} \pm 0.02$ & $3.20 \mathrm{~b} \pm 0.02$ \\
& Skin & $4.78 \mathrm{a} \pm 0.02$ & $4.47 \mathrm{~b} \pm 0.06$ \\
& Seed & $33.35 \mathrm{a} \pm 0.08$ & $29.69 \mathrm{~b} \pm 0.08$ \\
\hline
\end{tabular}

*TPC, Total phenolic content; TC, Tannin content. All data are based on the mean values \pm standard deviation. All experiments were performed in triplicate. The values with different letters within each row are significant difference

Comparative monomers composition and content in different tissues of grape: Fig. 2 showed that the (+)-catechin concentrations were high in all tissues of grape and the corresponding proportion was higher in seeds than other tissues, followed by peduncles and fleshes. Besides, the content of (+)-catechin in seeds $\left(3.30,7.62 \mathrm{mg} \mathrm{g}^{-1}\right.$ for five-year and tenyear grapevines grape respectively) was significantly higher in skins $\left(0.13,0.11 \mathrm{mg} \mathrm{g}^{-1}\right.$ in five-year and ten-year grapevines grape respectively), which agrees well with previous studies ${ }^{19}$. Moreover, the concentration of (+)-catechin in seeds of tenyear grapevines grape was higher than that of five-year one. On the contrary, the (-)-epicatechin concentrations (Fig. 3) in tissues were lower or similar to those of $(+)$-catechin, with the regularity of distribution similar to (+)-catechin. (+)-Catechin gallate were not detected in flesh, but showed highest concentration in seed, followed by skins (Fig. 4). The Fig. 4 showed that extremely low levels of (-)-epicatechin gallate detected in the skin of five-year grapevines grape, which did not occur in ten-year one. Nevertheless, we could not rule out the presence of (-)-epicatechin gallate in ten-year grapevines grape (Fig. 5).

The (-)-epigallocatechin (Fig. 6) was the relatively abundant compound in all the seudies flavan-3-ol monomers

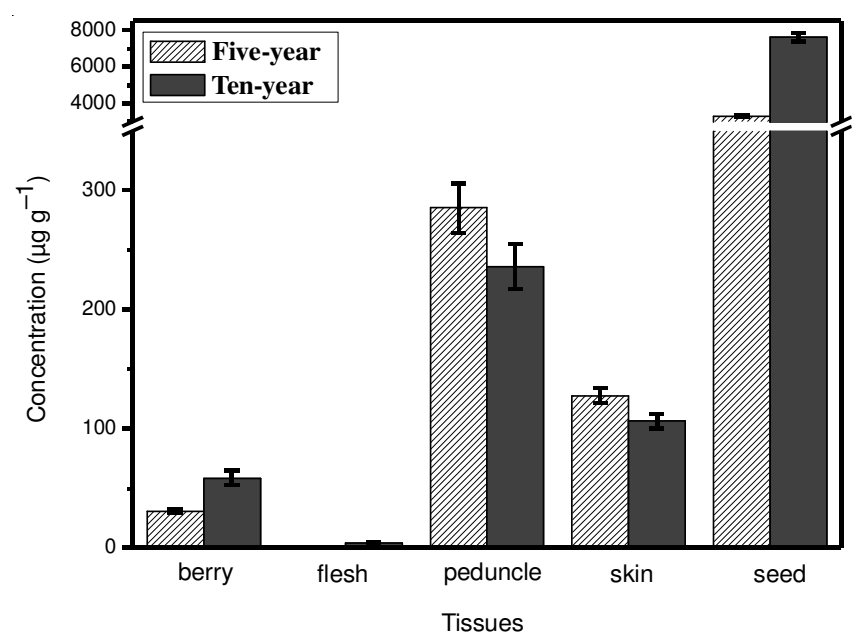

Fig. 2. Concentration of (+)-catechin in different tissues of different grapevine age grape 


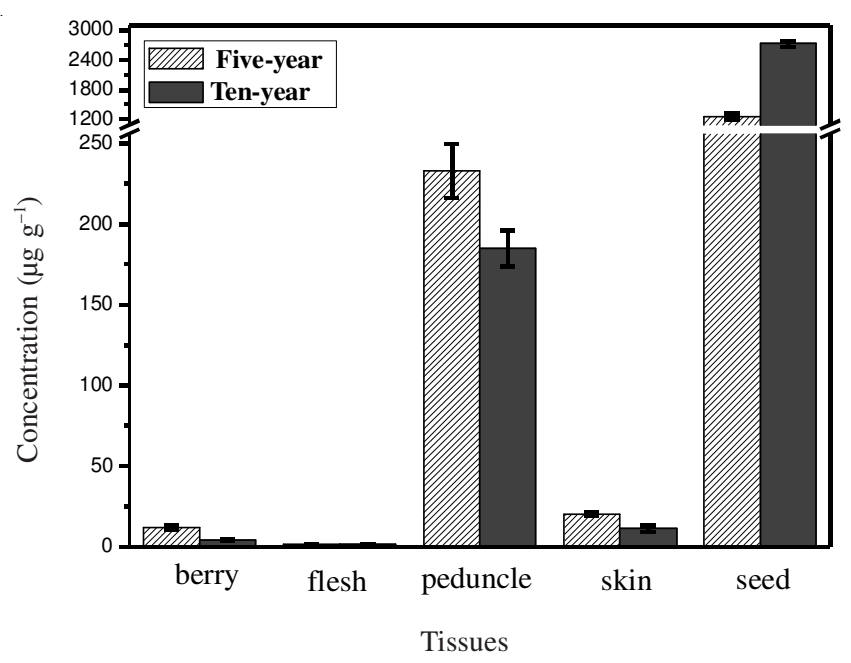

Fig. 3. Concentration of (-)-epicatechin (EC) in different tissues of different grapevine age grape

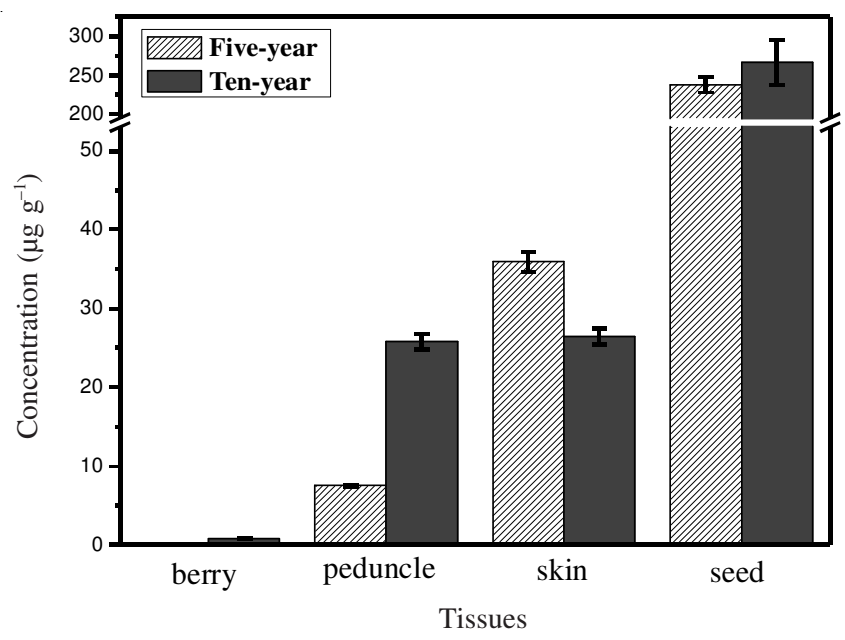

Fig. 4. Concentration of (-)-catechin gallate (EGCC) in different tissues of different grapevine age grape. (EGCC was not detected in berry of five-year grapevines grape. EGCC were not detected in flesh of five-year and ten-year grapevines grape)

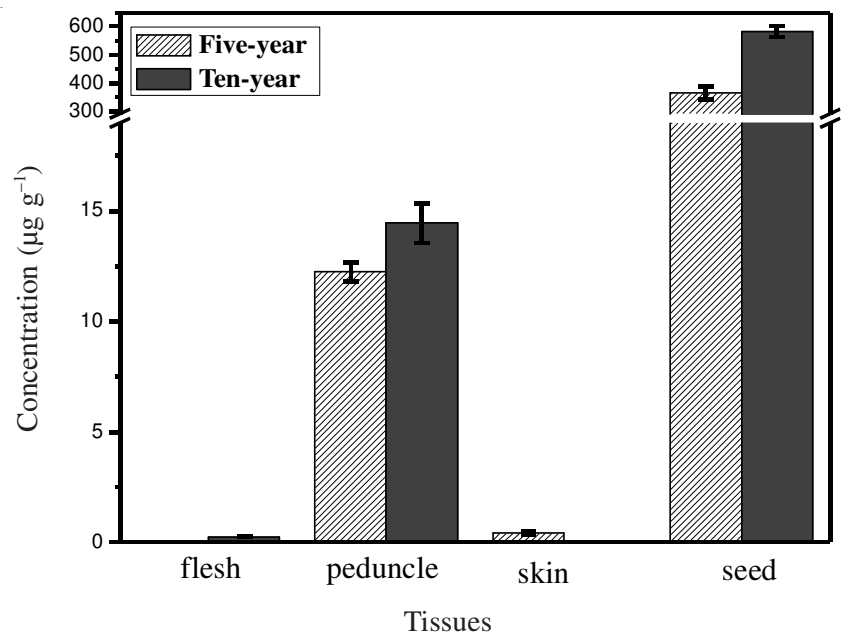

Fig. 5. Concentration of (-)-epicatechin in different tissues of different grapevine age grape. (ECG was not detected in berry of five-year and ten-year grapevines grape. ECG was not detected in flesh of five-year grape and not detected in skin of ten-year grapevines grape) and its concentration decreases in the order of seed $>$ peduncle $>$ skin $>$ flesh. For instance, the content in the seeds of ten-year grapevines grape reached $14.89 \mathrm{mg} \mathrm{g}^{-1}$ that was almost as quintupling as that of five-year's, Meanwhile, the content of $(+)$-gallocatechin grade in both skins and seeds of ten-year grapevines grape $\left(0.30\right.$ and $\left.1.35 \mathrm{mg} \mathrm{g}^{-1}\right)$ were higher than those of five-year ( 0.25 and $0.33 \mathrm{mg} \mathrm{g}^{-1}$, respectively) (Fig. 7). However, the distribution of gallocatechin gallate in different tissues was quite different. The contents in the peduncle of five-year and ten-year grapevines grapes were 0.051 and $0.011 \mathrm{mg} \mathrm{g}^{-1}$, respectively. The gallocatechin gallate was found in the flesh of ten-year grape $\left(0.00073 \mathrm{mg} \mathrm{g}^{-1}\right)$, but was not detected in the five-year one (Fig. 8), which may be due to the low level of gallocatechin gallate in the tested samples. About the distribution of (-)-epigallocatechin gallate in different tissues, it's concentration in the seed, skin and peduncle of ten-year grape were all higher than those of five-year (Fig. 9).

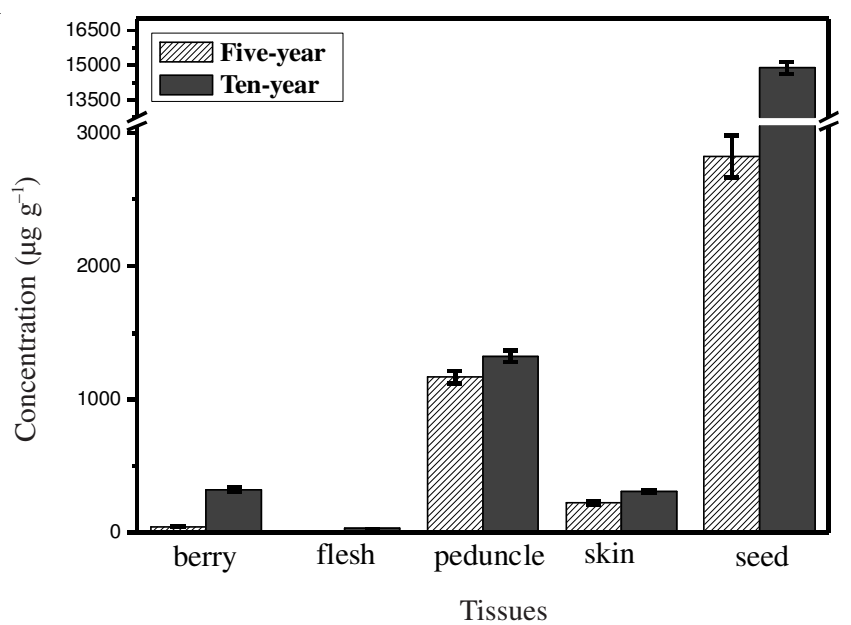

Fig. 6. Concentration of (-)-epigallocatechin in different tissues of different grapevine age grape

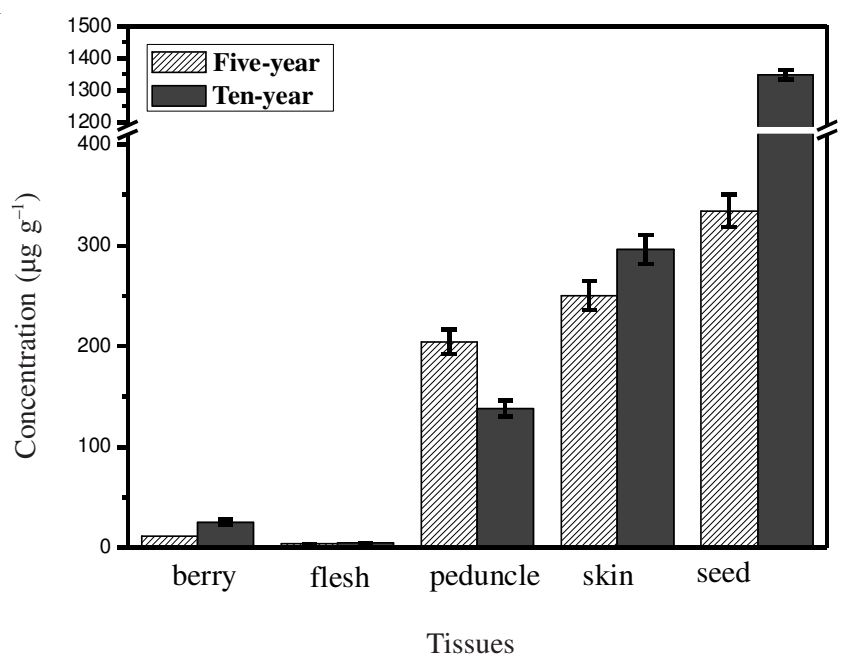

Fig. 7. Concentration of (+)-gallocatechin grade in different tissues of different grapevine age grape

It is interesting to note that (+)-catechin gallate was found in the seeds and skins of same year of grape, but not in their flesh, which could be ascribed to the facile method that we used to prepare grape samples. The whole grapes berry was 
crushed by juice extraction device, by which seeds might not be crumbled completely. In addition, the skin was immersed for a short time, so that the composition of flavan-3-ol in seeds and skins [such as (-)-catechin gallate] were not mixed with grape juice, which indicated that the composition of grape could immerse into the wine if appropriate time of immersing and seed broking adopted.

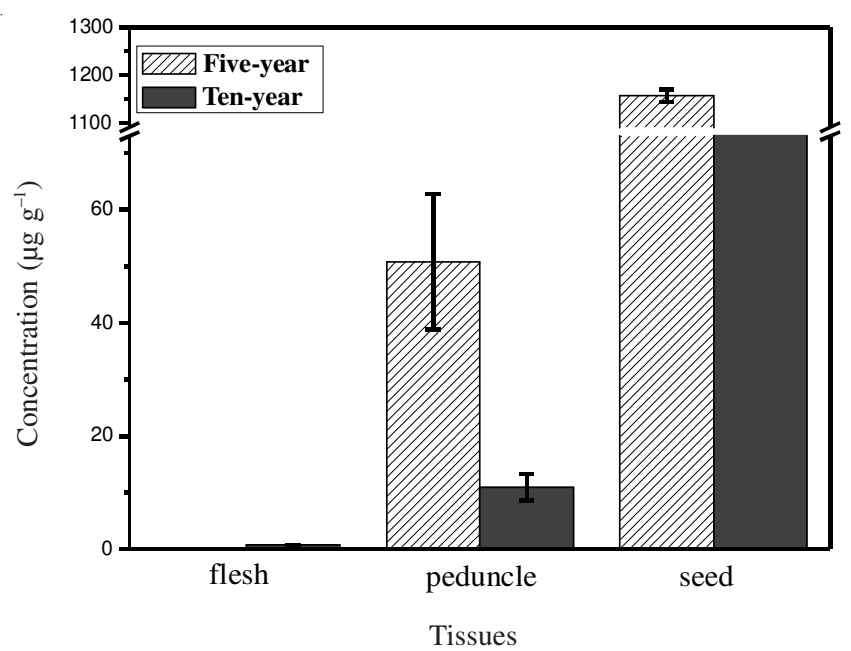

Fig. 8. Concentration of gallocatechin gallate in different tissues of different grapevine age grape. (Gallocatechin gallate was not detected in berry and skin of five-year and ten-year grapevines grape. Gallocatechin gallate was not detected in flesh of five-year grapevines grape

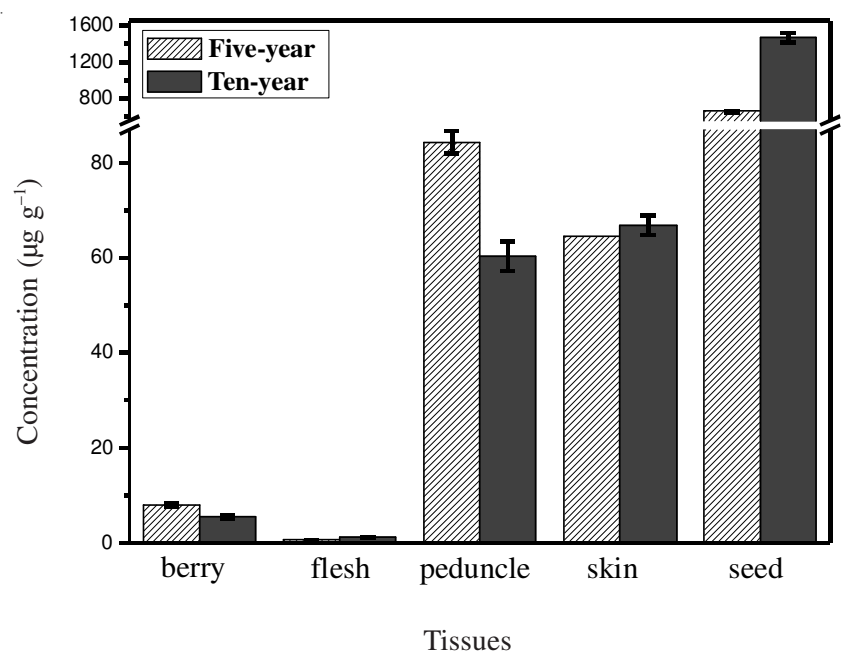

Fig. 9. Concentration of (-)-epigallocatechin gallate in different tissues of different grapevine age grape

Comparing different monomers composition and content in the same tissue: For Cabernet sauvignon seeds, the concentrations of flavan-3-ol monomers $((+)$-catechin, (-)-epicatechin and (-)-epicatechin gallate) decreased continuously from veraison to maturity stage ${ }^{25}$ and the seeds in the tissues of five-year and ten-year grape contained the most abundant flavan-3-ol monomers, which is consistent with previous data ${ }^{26-28}$. As shown in Fig. 10, the concentration of flavan-3-ol monomers reached highest value in the seeds. Furthermore, the concentration of the same monomers in the seeds of ten-year grape was significantly higher than that of five-year one, which implies that the grapevine age could affect the flaovl-3-ol monomers composition in vinifera fruit between five-year and ten-year grape.

The flavan-3-ol monomers of gallocatechin gallate, (-)epicatechin gallate presented in the flesh of ten-year grape, but not detected in five-year one (Fig. 11). While the content of (+)-catechin, (-)-epigallocatechin and (-)-epigallocatechin gallate, at five-year $\left(0.00036,0.0014\right.$ and $0.00064 \mathrm{mg} \mathrm{g}^{-1}$, respectively) were significantly lower than those at ten-year (0.0040, 0.0015 and $0.0012 \mathrm{mg} \mathrm{g}^{-1}$, respectively) (Fig. 6), which also indicates that the grapevine age could affect the level of monomeric flavan-3-ol.

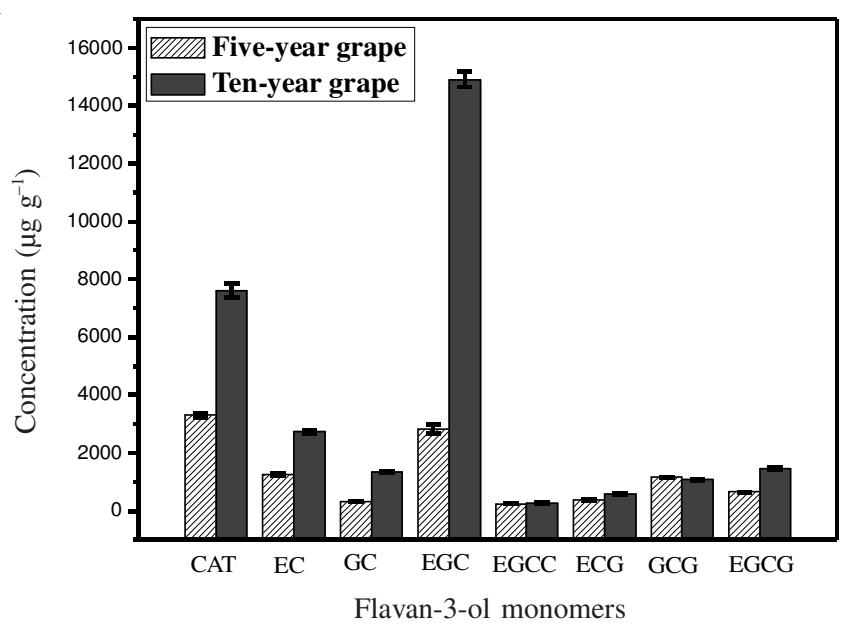

Fig. 10. Concentration of eight flavan-3-ol monomers in the seed of different grapevine age grape

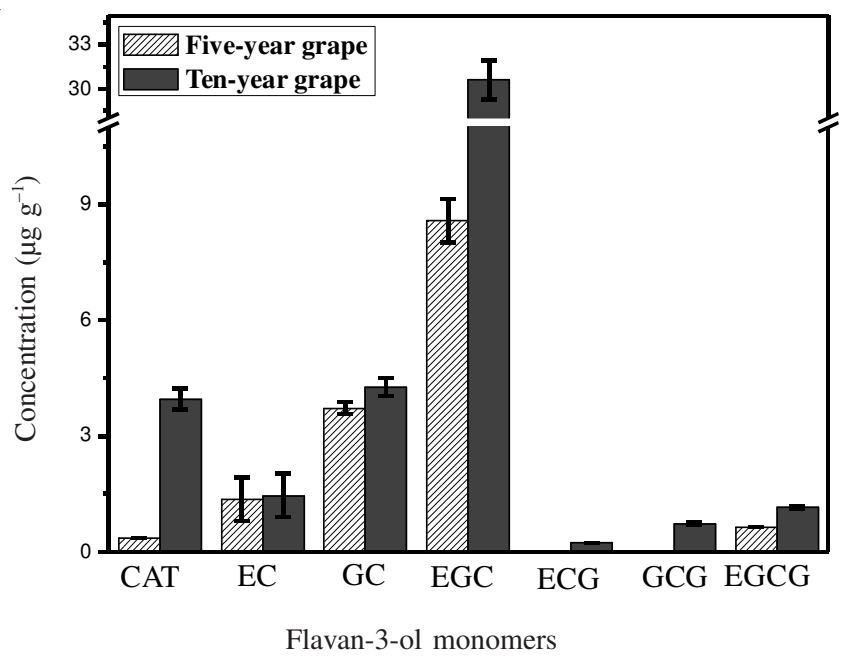

Fig. 11. Concentration of eight flavan-3-ol monomers in the flesh of different grapevine age grape. (EGCC was not detected in five and ten-year grape, ECG and GCG were not detected in five-year grape)

It is noted that the most abundant monomers of flavan-3ol were present in peduncle (all eight standard substances were detected) (Fig. 12), which is consistent with previous data ${ }^{29-33}$. The concentration of flavan-3-ol monomers was second higher in seeds, though some monomers showed higher concentration in skins (Fig. 13), i.e. (+)-catechin and (-)-epicatechin. In addition, the highest content of monomers was (-)-epicatechin that is more concentrated in ten-year grapevines grape than five-year one. The concentration of eight flavan-3-ol monomers 
in the berry of different grapevine age grapes was shown in Fig. 14, from which it is concluded that the concentration of each monomer in the berry was lower than the respective sum of the concentration in the seed, peduncle and skin. The founding indicates that the sample preparation and immersion time could influence the extraction rate of flavan-3-ols from grapevine. Moreover, the concentration of each monomer flavan-3-ol in the berry was higher in ten-year grapevines grape than in fiveyears one, which implies that the grapevine age could play an important role in determining the concentration of flavan-3ol monomer in the same tissue.

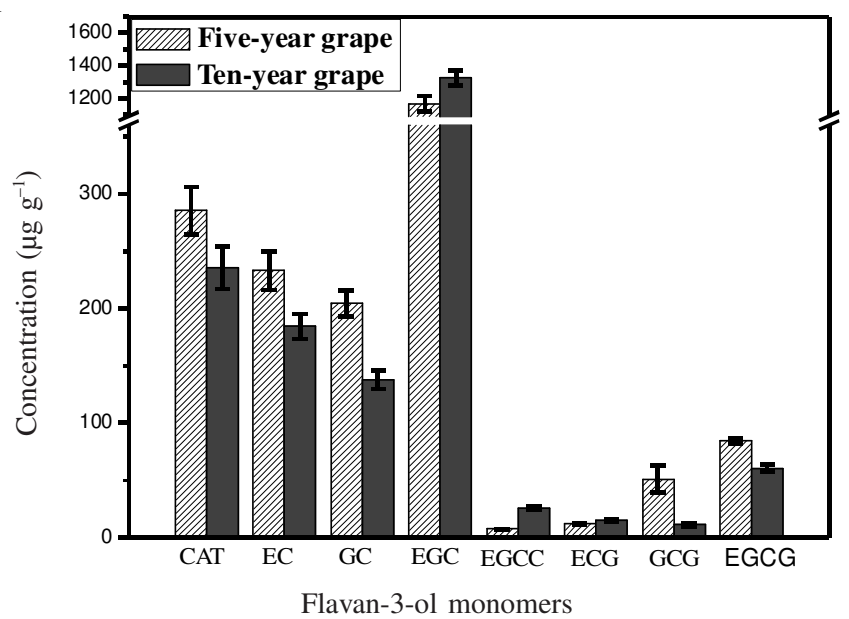

Fig. 12. Concentration of eight flavan-3-ol monomers in the peduncle of different grapevine age grape

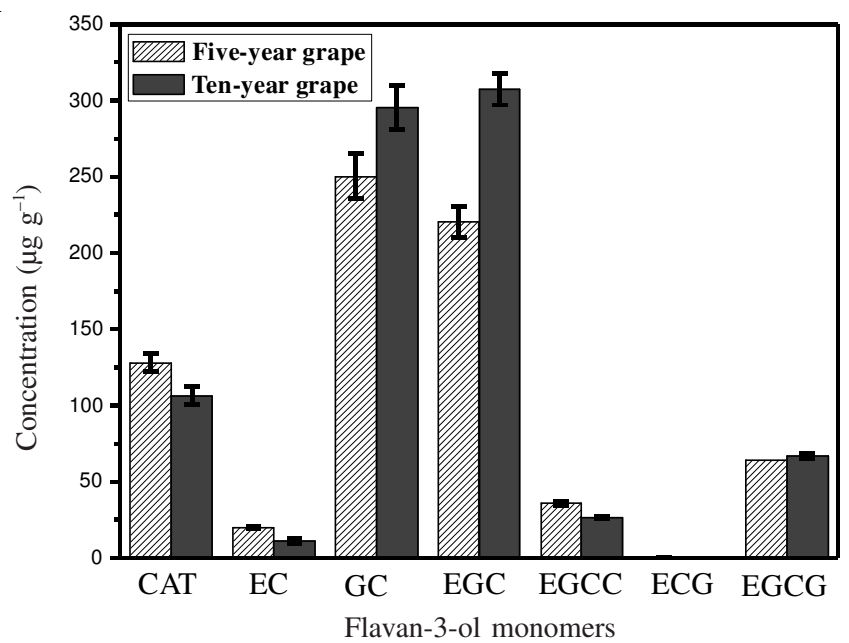

Fig. 13. Concentration of eight flavan-3-ol monomers in the skin of different grapevine age grape. (GCG were not detected in five-year and tenyear grapevines grape, ECG was not detected in ten-year grapevines grape)

\section{Conclusion}

We have investigated for the first time that the influence of grapevine age on the flavan-3-ol monomers composition and the content of Cabernet sauvignon from Yantai (the major wine region of China) and demonstrated that some global factors such as the content of total phenol and total tannins in seeds, peduncles and skins were useful tools to discriminate five-year and ten-year grapes. Furthermore, we confirmed that flavan-3-ol monomers concentrations in the seed of ten-year

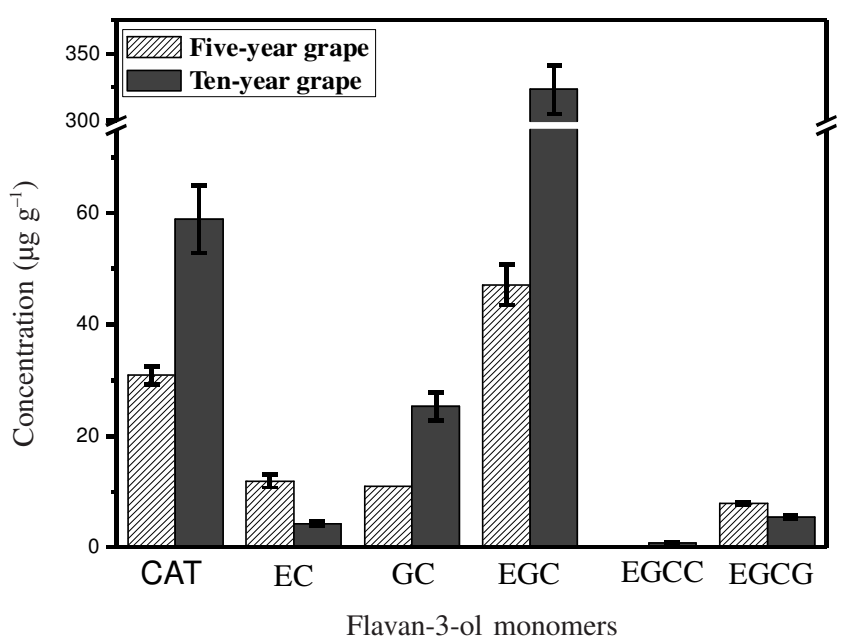

Fig. 14. Concentration of eight flavan-3-ol monomers in the berry of different grapevine age grape. (EGCC was not detected in five-year grapevines grape, ECG, GCG were not detected in five-year and ten-year grapevines grape)

grapevines grape were higher than that of five-year, though both of which contained abundant monomers. The total concentration of each monomer in the berry was lower than the respective sum of the concentration in the seed, flesh and skin, which indicated that the sample preparation and immersion time, could influence the extraction rate of flavan-3-ols from grapevine. Moreover, the concentration of each monomer flavan-3-ol in the berry was higher in ten-year grapevines grape than in five-years one, which implied that the grape age could play an important role in determining the concentration of flavan-3-ol monomers in the same tissue. Whether the concentration of flavan-3-ol monomers in grape will indeed increasing with the extended of grapevine age or not, whether their contents can reach the maximum levels in grape growth process, further research is needed to explain these questions as well as more the specific mechanism by which the variation of the concentration of flavan-3-ol monomers.

\section{ACKNOWLEDGEMENTS}

This work was partially supported by the Agricultural Seed Engineering of Shandong Province and gratefully thank Shandong Analysis and Test Center (Shandong Academy of Sciences) for technical assistance in the HPLC analysis. The authors are also grateful for financial support from the Foundation of Shandong Province (ZR2011CM032) and the Development Project of Shandong Province (2012GGB01059).

\section{REFERENCES}

1. E. Haslam, Phytochemistry, 19, 2577 (1980).

2. V. Cheynier, in ed.: S. Martens, D. Treutter and G. Forkmann, In Polyphenols 2000, Freising: Weihenstephan Germany (2002).

3. M.L. Revilla and M. González-San José, Int. J. Food Sci. Technol., 38, 29 (2003).

4. H. Wang, G.J. Provan and K. Helliwell, Trends Food Sci. Technol., 11, 152 (2000).

5. L. Rapport and B. Lockwood, Pharmaceut. J., 266, 581 (2001).

6. K.E. Heim, A.R. Tagliaferro and D.J. Bobilya, J. Nut. Biochem., 13, 572 (2002)

7. M. Bourzeix, D. Weyland and N. Heredia, Bull. OIV, 59, 1171 (1986).

8. J.M. Ricardo da Silva, J. Rigaud, V. Cheynier, A. Cheminat and M. Moutounet, Phytochemistry, 30, 1259 (1991). 
9. M.T. Escribano-Bailón, M.T. Guerra, J.C. Rivas-Gonzalo and C. SantosBuelga, Zeitschrift Forsch Lebensmitteluntersuchung und-Forschung, A, 200, 221 (1995).

10. C. Santos-Buelga, E. Francia-Aricha and M. Escribano-Baióln, Food Chemistry, 53, 197 (1995).

11. T. Fuleki and J.M.R. da Silva, J. Agric. Food Chem., 45, 1156 (1997)

12. V.A.P.D. Freitas and Y. Glories, J. Sci. Food Agric., 79, 1601 (1999).

13. V. De Freitas, Y. Glories and A. Monique, Am. J. Enol. Viticult., 51, 397 (2000).

14. H. Düring and A. Davtyan, Vitis, 41, 63 (2002)

15. H. Çoban, Asian J. Chem., 19, 4052 (2007).

16. Australian Centre for International Agricultural Research, Tannins in Livestock and Human Nutrition. ACIAR Canberra, Australia., edn. 92 (1999).

17. M.O. Doweny, J.S. Harvey and S.P. Robinson, Aust. J. Grape Wine Res., 9, 15 (2003).

18. J. Thorngate III and V. Singleton, Am. J. Enol. Viticult., 45, 259 (1994)

19. M. María, G.C. Carmen, O.L. Begoña Bartolomé and M.R. Jorge, J. Agric. Food Chem., 51, 6475 (2003).

20. L. Bénédicte, C. Kleopatra and T. Pierre-Louis, Food Chem., 126, 1991 (2011).

21. O.S. Elías, P.N. Álvaro, L.S. Remigio, Z.M. Fernando, R.D. Jorgem and O.L. Silva, J. Agric. Food Chem., 58, 3591 (2010).
22. K. Kantz and V. Singleton, Am. J. Enol. Viticult., 41, 223 (1990).

23. V. Kovac, E. Alonso and E. Revilla, Am. J. Enol. Viticult., 46, 363 (1995).

24. J. Ricardo-da-Silva, V. Cheynier, A. Samsom and M. Bourzeix, Am. J. Enol. Viticult., 44, 168 (1993).

25. B. Sun, J.M. Ricardo-da-Silva and I. Spranger, J. Agric. Food Chem., 46, 4267 (1998).

26. J. Ricardo-da-Silva, A. Belchior, M. Spranger, and M. Bourzeix, Sci. des Aliments, 12, 223 (1992).

27. V. Singleton, Basic Life Sciences, 59, 859 (1992).

28. T. Escribano-Bailon, Y. Guitéirrez-Feránndez, J.C. Rivas-Gonzalo and C. Santos-Buelga, J. Agric. Food Chem., 40, 1794 (1992).

29. J.M. Ricardo-da-Silva, In Proceedings of the First Symposium : In Vino Analytica Scientia, Bordeaux, France, pp. 101-113 (1997).

30. J.M. Souquet, V. Cheynier, F. Brossaud and M. Moutounet, Phytochemistry, 43, 509 (1996).

31. C. Prieur, J. Rigaud, V. Cheynier and M. Moutounet, Phytochemistry, 36, 781 (1994).

32. J.M. Souquet, B. Labarbe, C. Le Guerneve, V. Cheynier and M. Moutounet, J. Agric. Food Chem., 48, 1076 (2000).

33. C.P. Des Gachons and J.A. Kennedy, J. Agric. Food Chem., 51, 5877 (2003). 